\title{
Series
}

DOI $10.1007 / \mathrm{s} 12038-015-9504-x$

\section{What history tells us XXXVI. \\ Reverse transcriptase and Lamarckian scenarios of evolution}

\author{
Michel Morange \\ Centre Cavaillès, République des Savoirs: Lettres, Sciences, Philosophie USR 3608, Ecole \\ Normale Supérieure, 29 Rue d'Ulm, 75230 Paris Cedex 05, France \\ (Fax, 33-144-323941; Email, morange@biologie.ens.fr)
}

\section{Introduction}

The hypothesis that some molecular mechanisms might open the door to an inheritance of acquired characters and a return of Lamarckism has been recurrently proposed during the last 50 years, despite the long complicity between molecular biology and Darwinism exemplified in the Central Dogma. Today, epigenetic modifications (Jablonka and Lamb 2005) and the bacterial and archaeal CRISPR system of antiviral defence (Koonin and Wolf 2009; Childs et al. 2012) have been suggested to be at 'the interface of Lamarck and Darwin' (Childs et al. 2012, p. 2015).

The protovirus model proposed by Howard Temin in 1971 was probably the first of these 'heretical' models (as far as the Darwinian theory is concerned). I will successively describe the context in which this model was constructed, the experimental evidence supporting as well as challenging it, its return through the experimental arguments opposing the random nature of mutations produced by John Cairns (Cairns et al. 1988), and the final demonstration by Cairns himself that the so-called 'directed mutations' were not the result of reverse transcription (Foster and Cairns 1992). I will argue in the conclusion that the purported role of reverse transcriptase in evolution was a perfect 'Lamarckian' model, more 'Lamarckian' than most of the extant resurgences of Lamarckism.

\section{The protovirus model}

The discovery of reverse transcriptase has already been well documented. Through his own experiments with different inhibitors of RNA and DNA synthesis, Howard Temin was convinced very early that the transformation of cells by the Rous sarcoma virus required the copying of the viral RNA genome into a double-stranded DNA, and its insertion into the cellular genome. In 1964, he provided the results of hybridization experiments demonstrating in the genome of infected cells the presence of DNA sequences able to hybridize with the viral RNA (Temin 1964). Historians have shown that these experiments did not convince the community of biologists, not because of the allegiance of the latter to the Central Dogma, but because the signals were low and not easily distinguishable from the background noise (Marcum 2002; Fisher 2010). The demonstration of the model came from the isolation and characterization in 1970 by David Baltimore and Howard Temin himself of an RNAdependent DNA polymerase (Baltimore 1970; Temin and Mizutani 1970).

Before this confirmation, Temin had already argued that the mechanisms used by the virus to insert its genome into the genome of the host were probably derived from normal physiological mechanisms, acting on 'protoviruses' present in the genome to control cell differentiation, antibody formation, and memory (Temin 1964). In 1971, he suggested that such mechanisms of copying mRNA into DNA and the subsequent insertion into the genome might occur in germ cells, and have evolutionary consequences (Temin 1971). The relations between the transforming retrovirus and the normal protovirus were not absolutely clear. Nevertheless, Temin tried to account for all forms of cancer by similar mechanisms: cancer was always the consequence of a modification of the mechanisms of informational transfer from

Keywords. Evolution; Howard Temin; Lamarckism; neo-Lamarckism; protovirus; reverse transcriptase 
DNA to RNA to DNA. Baltimore also considered that the RNA-dependent RNA polymerases that he had isolated from other viruses and characterized probably existed in normal, uninfected cells (Stampfer et al. 1972) in which they had a role in the transfer of information. It was also suggested that the recently observed amplification in amphibians of the DNA that codes for ribosomal RNA might result from a retro-transcription (Crippa and Tocchini-Valentini 1971).

\section{The model was rapidly compared with a wealth of new observations}

The existence in non-infected murine and avian cells of an RNA-directed DNA polymerase was demonstrated by Temin (Coffin and Temin 1971; Kang and Temin 1972, 1973; Bauer and Temin 1979), and rapidly confirmed by the group of George Todaro (Ross et al. 1971; Scolnick et al. 1971). The presence of this polymerase could explain the previous controversial observation of the so-called informational DNA (I-DNA) and informosomes in the cytoplasm (Bell 1969). I-DNA was not a copy of DNA, but a retrocopy of RNA.

Unfortunately, these early observations were not confirmed, and the presence of a reverse transcriptase was increasingly considered as a sign of an infection by a retrovirus. It was the presence of reverse transcriptase activity that led to the discovery of human immunodeficiency virus (HIV) in 1983 (Barré-Sinoussi et al. 1983).

The development, from the beginning of the 1970s, of the tools of genetic engineering permitted a rapid accumulation of observations in eukaryotes that proved that RNA was copied into DNA during evolution, but at the same time made the physiological significance of these observations problematic. Since most cellular RNAs are spliced after their synthesis, the action of reverse transcriptase in the cytoplasm would generate spliced copies of the genes that were rapidly discovered among the non-functional copies of genes named pseudogenes. They were confirmed to be inactive, from the absence of upstream sequences necessary for their expression.

These observations were concomitant with the discovery of large families of transposons in the eukaryotic genome, but also of retroposons. The latter included the previously described retroviruses, and also a huge number of newly described nonviral retroposons (Weiner et al. 1986). In 1980, Leslie Orgel and Francis Crick, and W Ford Doolittle and Carmen Sapienza proposed that transposons and retroposons were molecular parasites (Doolittle and Sapienza 1980; Orgel and Crick 1980). The hope that reverse transcription could be an important participant in cell physiology and in evolution faded away. However, it did not fully disappear (Marx 1982; Lewin 1983). It was suggested that it might have been important at the origin of life (Balasubramanian and Seetharamulu 1980). The errorprone reverse transcriptase might have allowed an increase in the frequency of mutations through a cycling of information between RNA and DNA (Reanney 1984); gene conversion could have permitted mutations in inactive pseudogenes to be introduced into functional genes. From experiments initiated at the end of the 1970s, EJ Steele had been convinced of the existence of an inheritance of acquired immune characteristics, and of the role of reverse transcriptase in this process (Gorczynski and Steele 1980, 1981; Steele and Pollard 1987).

\section{The final twilight of an evolutionary role of reverse transcriptase}

A role for reverse transcriptase in evolution was abruptly resurrected when John Cairns reported his observations on 'directed mutations' in bacteria in 1988 (Cairns et al. 1988). James Shapiro had shown in 1984 that the appearance of mutations corresponding to an araB-LacZ cistron fusion could not be accounted for by stochastic models of hereditary mutations (Shapiro 1984). Through a precise statistical analysis of the formation of mutants, Cairns and his collaborators demonstrated that in the case of a nonlethal selective procedure, the time of appearance and the distribution of mutations are different from the random ones observed by Salvador Luria and Max Delbrück in their famous 1943 paper (Luria and Delbrück 1943), and they suggested that bacteria were able to choose the mutations that they should produce. The mechanism that Cairns favoured was the reverse transcription of mRNAs permitting bacteria to adapt to new nutrients. The way in which the variant favourable forms of mRNAs were selectively recognized was not precisely described.

Cairns's article initiated a flood of publications and a huge debate in which many eminent molecular biologists participated (see, for instance, Stahl 1992). Not only did Cairns's observations show the limits of one of the iconic experiments of molecular biology, but they were shaking one of the pillars of Darwinism - the randomness of mutations. The debate lasted for seven years, and a consensus was reached that the mutations were not directed (Shapiro 1995), but resulted from an increase in the general rate of mutation, and a rapid diffusion of the favourable mutations by conjugation. Cairns himself afforded the strongest experimental arguments against an involvement of reverse transcriptase by showing that some of the adaptive mutations were due to suppressor mutations, unlinked to the gene ( $L a c Z$ ) under selective pressure (Foster and Cairns 1992)

\section{Conclusions}

Although he does not explicitly discuss the role of reverse transcription, James Shapiro still considers today that the 
genome is permanently rewritten through the natural genetic engineering ability of organisms (Shapiro 2011). It is no doubt possible to find post-1994 articles in which a role of reverse transcriptase in evolution is discussed. But too many obstacles have accumulated since the introduction of the model. Temin himself admitted that the major consequence of reverse transcription was a mutational load, even if he still believed that 'rarely, perhaps, integration of reverse transcripts also could have been a source of variation' (Temin 1985, p. 464).

Some lessons emerge from the historical sketch presented here. The first is that science functions quite well. Although Temin was deeply attached to the model that he proposed, and although this model was attractive, it never prevented him and others, including Cairns, from accepting the experimental facts that opposed the model.

The second lesson is that, when a mechanism is discovered, the first attitude of biologists is to consider that it must have been fully exploited by organisms. Such a conviction is probably a side-effect of the belief in the creative, opportunistic power of natural selection; the problem is that it is far from being always true! (For a counter example, see Morange 2007.)

The third, interesting lesson concerns the relation between this model and Lamarckism. Lamarckism is not equivalent to an inheritance of acquired characters: if such were the case, Darwin would be a Lamarckian! Lamarckism may be invested with different meanings, since the ideas of Lamarck were different from those of his successors, the American and French neo-Lamarckians. For Lamarck, evolution was the result of a physical trend towards complexity. In addition, organisms have the capacity to react against changes in their environment by transforming their habits and developing some of their organs, and transmitting these modifications to their progeny. American neo-Lamarckians kept the idea of a trend in evolution ('orthogenesis'), but this did not have the same physical foundation as it did for Lamarck. For French neo-Lamarckians, the environment could act directly on organisms and modify their structures, these modifications being transmitted to the progeny. The model elaborated by Cairns in 1988 was a perfect Lamarckian model in the sense of Lamarck. Bacteria in which an altered form of RNA permitted the use of a new nutrient reacted by producing more of this modified form of mRNA, which was preferentially retrotranscribed into the genome and transmitted to the progeny. Epigenetics is similarly considered Lamarckian, since epigenetic marks can be modified by the environment and these modifications (in rare cases) can be transmitted to the progeny. The active participation of organisms in the process and the adaptive value of these modifications are not obvious, making this model more 'French neo-Lamarckian' than classically Lamarckian. It is also the case for the recently demonstrated starvation-induced pattern of gene silencing by endogenous siRNAs in $C$. elegans and its transmission to the descent (Rechavi et al. 2014): the adaptive value of this modification is not demonstrated, and its persistence limited to a few generations. The case of the CRISPR system is more interesting: the adaptive value of the modification is obvious, and its stability through generations far stronger. Nevertheless, the acquired characters are more the direct result of a change in the environment (as in the neo-Lamarckian model) than a response of the organism, the result of its efforts to change its habits (as it was the case for Lamarck, and in the model proposed by Cairns). The role proposed for reverse transcription in evolution was perhaps the last (unsuccessful) attempt to find in molecular mechanisms strong support for the ideas of Lamarck.

\section{Acknowledgements}

I am indebted to David Marsh for his critical reading of the manuscript, and to Stuart Newman, who provided me recent references and helped me make the conclusion of this article more precise.

\section{References}

Balasubramanian R and Seetharamulu P 1980 Possible role of RNA-dependent DNA-polymerase in early stages of evolution. Orig. Life 10 271-275

Baltimore D 1970 Viral RNA-dependent DNA polymerase. Nature 226 1209-1211

Barré-Sinoussi F, Chermann J-C, Rey F, Nugeyre MT, Chamaret S, et al. 1983 Isolation of a T-lymphotropic retrovirus from a patient at risk for Acquired Immune Deficiency Syndrome (AIDS). Science 220 868-871

Bauer G and Temin HM 1979 RNA-directed DNA polymerase from particles released by normal goose cells. J. Virol. 29 $1006-1013$

Bell E 1969 I-DNA: its packaging into $I$-somes and its relation to protein synthesis during differentiation. Nature 224 326-328

Cairns J, Overbaugh J and Miller S 1988 The origin of mutants. Nature 335 142-145

Childs LM, Held NL, Young MJ, Whitaker RJ and Weitz JS 2012 Multiscale model of CRISPR-induced coevolutionary dynamics: diversification at the interface of Lamarck and Darwin. Evolution 66 2015-2029

Coffin JM and Temin HM 1971 Ribonuclease-sensitive deoxyribonucleic acid polymerase activity in uninfected rat cells and rat cells infected with Rous sarcoma virus. J. Virol. 8 630-642

Crippa M and Tocchini-Valentini GP 1971 Synthesis of amplified DNA that codes for ribosomal RNA. Proc. Natl. Acad. Sci. USA 68 2769-2773

Doolittle WF and Sapienza C 1980 Selfish genes, the phenotype paradigm and genome evolution. Nature 284 601-603 
Fisher S 2010 Not beyond reasonable doubt: Howard Temin's provirus hypothesis revisited. J. Hist. Biol. 43 661-696

Foster PL and Cairns J 1992 Mechanisms of directed mutation. Genetics 131 783-789

Gorczynski RM and Steele EJ 1980 Inheritance of acquired immunological tolerance to foreign histocompatibility antigens in mice. Proc. Natl. Acad. Sci. USA 77 2871-2875

Gorczynski RM and Steele EJ 1981 Simultaneous yet independent inheritance of somatically acquired tolerance to two distinct $\mathrm{H}-2$ antigenic haplotype determinants in mice. Nature $289678-681$

Jablonka E and Lamb MJ 2005 Evolution in four dimensions: genetic, epigenetic, behavioral, and symbolic variation in the history of life (Cambridge MA: The MIT Press)

Kang C-Y and Temin HM 1972 Endogenous RNA-directed DNA polymerase activity in uninfected chicken embryos. Proc. Natl. Acad. Sci. USA 69 1550-1554

Kang C-Y and Temin HM 1973 Early DNA-RNA complex from the endogenous RNA-directed DNA polymerase activity of uninfected chicken embryos. Nat. New Biol. 242 206208

Koonin EV and Wolf YI 2009 Is evolution Darwinian or/and Lamarckian? Biol. Direct 442

Lewin R 1983 How mammalian RNA returns to its genome. Science 219 1052-1054

Luria SE and Delbrück M 1943 Mutations of bacteria from virus sensitivity to virus resistance. Genetics 28 491-511

Marcum JA 2002 From heresy to dogma in accounts of opposition to Howard Temin's DNA provirus hypothesis. Hist. Phil. Life Sci. 24 165-192

Marx JL 1982 Is RNA copied into DNA by mammalian cells? Science 216 969-970

Morange M 2007 z-DNA: when nature is not opportunistic. J. Biosci. 32 657-661

Orgel LE and Crick FHC 1980 Selfish DNA: the ultimate parasite. Nature 284 604-607

Reanney D 1984 Genetic noise in evolution? Nature 307 318-319
Rechavi O, Houri-Ze'evi L, Anava S, Goh WSS, Kerk SZ, et al. 2014 Starvation-induced transgenerational inheritance of small RNAs in C. elegans. Cell 158 277-287

Ross J, Scolnick EM, Todaro GJ and Aaronson SA 1971 Separation of murine cellular and murine leukaemia virus DNA polymerases. Nat. New Biol. 231 163-167

Scolnick EM, Aaronson SA, Todaro G and Parks WP 1971 RNA dependent DNA polymerase activity in mammalian cells. $\mathrm{Na}$ ture 229 318-321

Shapiro JA 1984 Observations on the formation of clones containing araB-lacZ cistron fusions. Mol. Gen. Genet. 194 79-90

Shapiro JA 1995 Adaptive mutation: who's really in the garden? Science 268 373-374

Shapiro JA 2011 Evolution: a view from the $21^{\text {st }}$ century (Upper Saddle River NJ: FT Press Science)

Stahl FW 1992 Unicorns revisited. Genetics 132 865-867

Stampfer M, Rosbash M, Huang AS and Baltimore D 1972 Complementarity between messenger RNA and nuclear RNA from HeLa cells. Biochem. Biophys. Res. Commun. 49 217-224

Steele EJ and Pollard JW 1987 Hypothesis: somatic hypermutation by gene conversion via the error prone DNA - RNA - DNA information loop. Mol. Immunol. 24 667-673

Temin HM 1964 Homology between RNA from Rous sarcoma virus and DNA from Rous sarcoma virus-infected cells. Proc. Natl. Acad. Sci. USA 52 323-329

Temin HM 1971 The protovirus hypothesis: speculations on the significance of RNA-directed DNA synthesis for normal development and for carcinogenesis. J. Natl. Cancer Inst. 46 III-VII

Temin HM 1985 Reverse transcription in the eukaryotic genome: retroviruses, pararetroviruses, retrotransposons and retrotranscripts. Mol. Biol. Evol. 2 455-468

Temin HM and Mizutani S 1970 RNA-dependent DNA polymerase in virions of Rous Sarcoma Virus. Nature 226 1211-1213

Weiner AM, Deminger PL and Efstratiadis A 1986 Nonviral retroposons: genes, pseudogenes, and transposable elements generated by the reverse flow of genetic information. Annu. Rev. Biochem. 55 631-661 